\title{
The Volitive and the Executive Function of Intentions
}

\author{
CHRISTOPH LUMER
}

\author{
Philosophy Department, University of Siena (Italy) \\ lumer@unisi.it
}

\begin{abstract}
Many philosophers of action conceive intentions functionally, as executive states: intentions are mental states that represent an action and tend to cause this action. In the philosophical tradition another function of intentions, which may be called "volitive", played a much more prominent role: intentions are mental states that represent what kind of actions we want and prefer to be realized and thus synthesize in a possibly rational way our motivational, desiderative and perhaps affective as well as cognitive attitudes towards this action. In the paper it is argued that intentions must fulfil both functions. Then a concept of 'intention' is developed that integrates both functions.
\end{abstract}

Keywords: intention; functions of intentions; executive function; volitive function; dissociation of volition and execution; Bratman; Mele

\section{Two Functions of Intentions}

Michael Bratman's book "Intention, Plans, and Practical Reason" [Bratman 1987] made popular, among others, a certain functional view of intentions. According to this view, intentions are executive states, i.e. they are mental states that represent an action, tend to cause the represented action as well as guide and sustain its execution. ${ }^{1}$ Many philosophers since then have accepted this thesis [Adams 1994; 2007; Adams \& Mele 1989; McCann 1998; Mele 1992, 72; 130; 136; 144; and at present probably it represents the most broadly accepted view in philosophy of action about the nature of intentions.

The present (at the beginning of the third millennium) popularity of this theory constitutes a rather radical and important change in philosophy of action because in the philosophical tradition another function of intentions played a much more prominent role. This function may be called the "volitive" function. That intentions have a volitive function here shall mean: intentions are mental states that represent what kind of actions we want and prefer to be realized and thus express and

1 Bratman was not the first who held this functional view. Already in 1984 Myles Brand introduced a definition of 'intention', according to which intentions are those states that proximally cause an action [Brand 1984, 174]. Adams [1986] defended the functional view as well. However, the functional idea is still much older. Locke e.g. took volitions, i.e. intentions in the traditional terminology, to be exertions of the capacity of our soul to initiate, continue as well as to stop movements of our body by thoughts, which command the execution of these movements [Locke $<1689>2004$, II,xxi,5].

Proceedings of the "XXII. Deutscher Kongresses für Philosophie", 11-15 September 2011, Munich. Internet publication. 
synthesize our motivational, desiderative and perhaps affective as well as cognitive attitudes towards this action and its alternatives; and this synthesis is or could be brought about at least in part by deliberation. ${ }^{2}$ To be sure, philosophers mostly did not use the word "intention", in the tradition they often spoke of "volitions" or "acts of will". Practical philosophers were particularly interested in this volitive function because they took it to be the result of our practical deliberation, which they studied with the hope to improve it and make it rational and thus making the resulting action rational as well.

The basic claim of this paper is the Two-Function Thesis: Full-fledged or real (implementation ${ }^{3}$ ) intentions have to fulfil both functions, the volitive and the executive function. In the remaining part of this paper this thesis will be defended and elaborated.

\section{Why Full-fledged Intentions Must Fulfil Both, the Volitive and the Executive Function}

The volitive and the executive function of intention do not exclude each other; i.e. one and the same mental state can fulfil them both. This holds because they are defined functionally, and the two functions do not exclude each other. But why full-fledged or real intentions must have both functions - as my basic thesis says? The reason for this lies in the very nature of actions. The particular significance and importance of actions consists in the fact that, by acting, the psychic kernel of persons with its preferences and beliefs has the power to control - directly and, via predicted longer causal chains, also indirectly - (some parts of) the external and eventually also our internal world. Intentions are the key elements in these processes: their volitive function represents the quintessence of what the psychic kernel of the person wants in this particular situation; their executive function, on the other hand, represents the power to control the world. Both functions of intentions are needed for fulfilling this key position and for constituting actions. Intentions without executive function would be powerless desires; they would not enable us to control the world and condemn us to remain passive spectators, suffering from our unfulfilled desires. Intentions without volitive function, on the other hand, would be blind powers without a person behind them. It would not be us who are controlling the behaviour; we would "act" like a robot. And our "actions" or, more precisely, our controlled behaviour (if it were not completely organised by evolution) only accidentally would have any value for us,

2 For Aristotle the intention (prohairesis) is "what has been decided on by previous deliberation" [Aristotle, E.N. 1112a, 15-17]. Leibniz slightly criticises Locke's definition and defines 'volition' in opposition to it as "the effort or tendency towards what one finds to be good and against what one finds to be bad, in such a way that this tendency results immediately from the apperception of the good and the bad" [Leibniz <1704> 1996, II,xxi,5; my, C.L., translation]. For Kant, as usually, a volition is an exertion of the will; and the 'will' is defined, e.g., as: the capacity to act according to the representation of the laws; and because the deduction of actions from laws requires reason, the will is practical reason [Kant, Groundwork, BA $37=$ IV 412].

3 There are several types of intentions. In particular, we have to distinguish implementation intentions and goal intentions [Gollwitzer 1999], where goal intentions determine the goal to be reached but do not yet specify the details of the action, by which it shall be reached, in a way understandable to the executive system. Goal intentions are anchors for a further deliberation with the aim to specify the action and to form an implementation intention, which is understandable to the executive system. Of course, only implementation intentions but not mere goal intentions have a (direct) executive function. 
and in any case on average would have less value than the actions of a rational agent. So, a definition of 'intention' that tries to capture the practically pivotal position of intentions has to embrace both functions of intentions.

It might be helpful to explain this also in other words. Intentions are an essential element of actions. The very value expressed in the concept of action, i.e. what we (at least intuitively) appreciate in actions, as opposed to controlled mere behaviour, is their function to make us, or more precisely our internal kernel, control the world this is what makes up freedom and autonomy, at least in a rudimentary form. This function implies an influence of our self on the world. The pivotal element, the hinge of this relation is the intention, which connects the two parts. Its volitive function represents and enables the authorship of the self; and its executive function makes up the controlling influence on the world. Therefore, we need both, the volitive and the executive function of intentions for having a full-fledged and, in the sense explained, valuable intention and a full-fledged, i.e. free action.

The just given justification of the Two-Function Thesis is a practical justification. It shows why intentions with both functions are precious and much better than similar attitudes with only one of these functions. This practical justification is part of the methodological strategy of this paper, namely to explicate the concept of intention in such a way that the resulting definition captures (intensionally) what is valuable in the referent (or in the extension). ${ }^{4}$ Of course, this method is different from and goes beyond trying to capture a common sense meaning (of the word which expresses the concept) or the philosopher's meaning or intuition.

\section{Two Theories of Intentions as Mere Executive States - Bratman and Mele}

All this, in particular the Two-Function Thesis, seems to be so obvious that it is hard to imagine how it can be denied. However, a theory which holds that actions are only executive states does exactly this. So this view has to be considered. In particular, I will discuss Bratman's and Mele's versions of such a theory.

Bratman's most important ideas about our subject can be summarized in the form of three theses:

B1. Intentions as Executive States: Intentions are (defined as) executive states [Bratman 1987, 16; 108; (110)].

B2. Uniqueness of Intentions: The (executive) role of intentions cannot be played by other mental states like desires, beliefs, desire-belief pairs or value judgments, in particular optimality judgements [Bratman 1987, 8; 11; $18 \mathrm{f} . ; 22 ; 32 ; 37 \mathrm{f}$.].

B3. Intentions as Attitudes sui generis: Intentions are mental attitudes in their own right, or sui generis, i.e. not reducible to other common mental attitudes like beliefs, desires, desire-belief pairs [Bratman 1987, 10; 20; 110].

I want to argue that these three theses are false, or more precisely, because they all are highly ambiguous, that their most common interpretations are false.

The Intention-as-Executive-States thesis B1, without the parenthesis, can be understood as an analytical or as an empirical thesis, and the word "are" may be interpreted as the copula or as the predicate for the identity relation. It is not

\footnotetext{
4 This piece of method is part of a more comprehensive philosophical method and theory, which I
} have called "idealising hermeneutics". For a detailed description see: Lumer 2011. 
completely clear which interpretation Bratman has in mind, probably the analytical identity. I think, according to the common usage of the word "intention", it is indeed analytically true that one function of (implementation) intentions is to control actions. However, what has been said in the first two sections of this paper is a strong argument against the analytical identity; intentions have also the volitive function.

There seems to be an analytical argument for the Uniqueness-of-Intentions thesis B2: If intentions, desires, beliefs, value judgements are all defined as functional notions then they have different analytical functions. This implies that desires, beliefs etc. as such do not have the analytical function of intentions. So far so good. However this does not imply that desires, beliefs etc., apart from their analytical function cannot fulfil other functions as well. ${ }^{5}$

That intentions are attitudes sui generis, i.e. B3, again can be an analytical or an empirical thesis.

B3.1 (Analytical interpretation) definition of 'sui-generis intention': 'Intention' is a taxonomic notion, referring to certain mental attitudes that are not reducible to other common mental attitudes.

B3.2 (Empirical interpretation) Empirical Sui-generis Thesis: Functional intentions (executive states) are (as can be found out by observation) sui-generis intentions in the just (B3.1), taxonomically defined sense [Bratman 1987, 10; 20; 110].

Most likely Bratman holds both theses. One of his innovations in action theory was to introduce "intention" also as taxonomic notion - "taxonomic" in the sense of biological taxonomies: We study empirically and try to classify the various mental attitudes into a complete system of not overlapping classes according to their phenomenological qualities, their propositional contents, and their functions. Bratman sustains that there is such a taxonomic kind of mental states besides and on a par with beliefs, desires, emotions, feelings, moods, perceptions etc.; and this kind of states is called "intention". So, Bratman uses the term "intention" in two meanings, the taxonomical meaning (attitude sui generis) and the functional meaning (executive state).

Some arguments against the Empirical Sui-generis Thesis B3.2 are these. The main problem of sui-generis intentions is that they cannot fulfil the volitive function of intentions. They are just executive. Taxonomic intentions as such are not preferences, desires, volitions etc. and do not contain or express such pro-attitudes. In addition, again precisely because of their taxonomic autonomy, they are isolated and not connected to other mental states that are such pro-attitudes; there is no intuitive kind of "logic" that relates them to pro-attitudes. More specifically, sui-generis intentions as such are not the result of practical deliberations and are completely cut off from these deliberations. Therefore, actions on the basis of such intentions would not have the advantages sketched at the beginning of this paper, i.e. that by actions caused by intentions the kernel of our self controls the world. In Bratman's theory the intentions come out of nothing, and, therefore, they can neither be rational nor realize our practical autonomy, they simply remain unexplained.

Mele has tried to resolve some of these problems by complementing Bratman's Empirical Sui-generis Thesis (B3.2) by some hypotheses about empirical laws that connect sui-generis intentions to other mental attitudes [Mele 1992, 228-240]. The

5 McCann has shown that several other mental states in principle can fulfil many functions of intentions [McCann 1995, 575-582]. 
most important of these hypotheses is that optimality judgements about one's own actions by default cause sui-generis intentions to execute these actions [Mele 1992, 228-232]. This hypothesis implies an important structural suggestion with respect to the two functions of intentions emphasized in the preceding sections. According to Mele's theory, the volitive and the executive part of intentions would not reside in one and the same mental state but in two states that are closely connected by a causal relation. I will call this the "ontological dissociation of the two functions of intentions".

Mele's complement is an important improvement of Bratman's theory. However, many problems remain unsolved. If the ontological dissociation thesis were true the optimality judgements would completely control the sui-generis intentions. Then, however, two questions arise. First, why would there be any need of these sui-generis intentions? From an evolutionary standpoint they would be completely superfluous, the optimality judgements could directly be the set point determiner for the executive part of our action-generating mechanism; this speaks against the existence of suigeneris intentions. Now, sometimes in living beings there are features or items superfluous with respect to survival, which have not been erased by evolution. However, such features or items are relatively rare, such that the evolutionary superfluity of possible sui-generis intentions makes their existence rather unlikely. So, demonstrating this superfluity is not a knock-down argument but an argument of medium strenght against the existence of sui-generis intentions. Second, even if there were such a sui-generis intention the optimality judgement would already be an executive state that controls the external behaviour by causing the sui-generis intention; forming the sui-generis "intention" instead would already be the first step of execution.

\section{The Dissociation Problem}

According to the ideas exposed in the preceding sections, the definition of '(implementation) intention' seems to be straightforward: Implementation intentions are mental states that are volitive and executive. This would imply that mental states not fulfilling one of these functions would not be (implementation) intentions. However there may be cases of dissociation between the two functions that give rise to doubts about this definition.

There are two main forms of dissociation. The first form is causal dissociation. There is a certain kind of mental states that usually fulfils both functions. Both functions, however, are defined by the causal role the respective states play. (For the volitive function it is to integrate the various pro-attitudes and thus to be caused by them via a more or less complicate mechanism of integration; for the executive function it is to cause or at least to initiate the execution - which does not exclude that the execution then is interrupted.) One or both causal chains, now, may be cut off (and not only interrupted) by accident or other unfortunate circumstances. Certain forms of posthypnotic instructions, where the hypnotiser gives an instruction to execute a certain action later on and the hypnotized executes this instruction after the hypnosis, prima facie may be losses of the volitive function. Another, more fantastic example, would be hybrid creatures of a Brave New World type who have been created for serving their masters irrespective of any personal concern; so, if their masters say "do this!" then they immediately form the respective executive intention. Cases of the locked-in syndrome, on the other hand, prima facie are losses of the executive function: as a consequence of a dreadful trauma, the brain looses every or nearly every 
afferent and efferent contact to the rest of the body with the consequence to have no longer sensory perceptions and behavioural control of the body. The person may form "intentions" without any executive effect. (In the usual cases of executive accidents like forgetting the intention, akrasia etc., the executive function exists but it does not work properly.)

The other form of dissociation of the volitive and the executive function is ontological dissociation: both functions are fulfilled but they are realized by different mental states which, however, empirically are closely related and covary rather strictly. Mele's model of sui-generis intentions that are often caused by optimality judgements describes such a form of dissociation.

Before discussing the consequences of dissociation for the definition of 'intention' let us briefly consider the real existence or possibility of dissociation. With respect to the ontological dissociation, in the last section I have already advanced strong empirical objections against the hypothesis that mere executive states, in particular sui-generis intentions exist. However, these objections do not amount to a rejection of a logical or analytical possibility of such cases. Therefore, for a definition that shall also cover intentions in non-human beings, e.g. aliens or future people created by genetic or other technological manipulation, it would be wise to reckon with the possibility of ontological dissociation. - Apart from the hybrid beings, the other examples of causal dissociation were real examples, which, of course, have to be taken into account in a definition of '(implementation) intention'.

\section{Dealing with Dissociations in the Definition of 'Intention'}

How should the possible dissociations be dealt with in the definition of '(implementation) intention'? Let us consider causal dissociation first. The case of the hybrid beings who never had any volitive states combined with their executive states runs clearly counter the arguments advanced before (in section 2) in favour of intentions as necessary combinations of volitive and executive states. Accordingly, the hybrid beings' executive states would not be intentions. The same would hold for volitive states that never had any executive function. The case of the locked-in syndrome and perhaps posthypnotic instruction is different. Here the problem seems to be not the lacking of an executive (or volitive) function of the intention but a temporary or definite loss of a formerly existing function of the executive system, due to a dysfunction. Therefore, in such cases one might say: if there are phenomenal states that are of a kind that originally had (or in other beings usually has) the volitive as well as the executive function these states are still intentions even if one of these functions has gone lost.

With respect to a possible ontological dissociation of volitive and executive states the following holds: If there is no ontological dissociation the rules just explained apply. If, however, volitive and executive states ontologically dissociate but are nevertheless closely connected - as in Mele's model - then there are four main strategies to define 'intention' in the light of the requirement that intentions fulfil both functions.

1. Only states with both functions: Only states that fulfil both, the volitive as well as the executive function are intentions. Hence in case of an ontological dissociation there would not be an intention.

2. Unity of both states: In case of an ontological dissociation the unity of the tightly connected volitive and executive state is the intention. 
3. Only the executive state: In case of an ontological dissociation the executive state is the intention if it emerges from a corresponding volitive state.

4. Only the volitive state: In case of an ontological dissociation the volitive state is the intention if it directly causes a corresponding executive state.

Let us briefly discuss these possibilities:

1. Only states with both functions: To acknowledge only states with both, the volitive and the executive function as intentions is a puristic strategy. In a world with ontological dissociation it would exclude too much of what is sufficiently near to the ideal from being an intention. So, this kind of definition would be too narrow. The following three definitions are all more liberal in this respect, admitting intentions also in cases of ontological dissociation. In this respect the three remaining approaches are on a par. So further considerations should decide between them.

2. Unity of both states: To take the unity of the volitive and the executive state as the intention, on the one hand, comprises everything which is necessary for the existence of the intention in the intention itself. This advantage, however, is not so strong because it may be sufficient to require these necessary conditions as conditions and not as parts of the intention. On the other hand, the unity of two separate events or states may cause some problems for the determination of causal relations and of the intentions' time: If we say 'the intention caused the action', more precisely it would be the executive part of the intention that caused the action. And if we say 'she formed her intention at time $t^{\prime}$ this should refer either to the forming of the volitive or of the executive state. Therefore, it may be better to identify the intention with one state.

3. Only the executive state: An argument for declaring the executive states that emerged from volitions to be intentions would be that because the executive states already arise from volitions and add to this the executive function they comprise everything important for an intention in them. However, one could object to this, first, that if the volitive and the executive state dissociate and the volitive state controls or determines the executive state then the volitive state is already executive, whereas e.g. the sui-generis intention is already the first element of the execution process itself. Mere executive states are translations of the volition into a first grade machine code that is still mentally accessible. Second, apart from their function, mere executive states are no pro-attitudes in the narrow sense; they do not express that the subject is desideratively or emotionally or otherwise deliberatively bound to the action to be executed. Therefore, mere executive states fulfil a volitive function, if at all, only in a very, very broad sense.

4. Only the volitive state: The argument advanced against taking the executive states as the intentions, of course, is a straightforward argument for taking the volitive states as the intentions. If volitive states cause also the executive state they are in a certain sense executive above their volitive function. One might think that an analogous argument holds for the executive states: because they rise from volitive states and thus comprise them they are also, in a weak sense perhaps, volitive states. However, they are not; mere executive states, as just said, are not pro-attitudes in a somewhat narrow sense, and they are not the last step of making up one's mind about the options at hand. So there is a disanalogy here. Mere executive states that arise from volitions are not volitive, whereas mere volitive states that cause executive states are already executive. And this is a strong argument to choose among these two the volitive states as those that in cases of ontological dissociation are the implementation intentions.

The details of this definitional decision may be debatable. However, what is less debatable and important for capturing the essential function of intentions and actions 
is that only the combinations of volitive and executive states are implementation intentions. Mere executive states are not yet intentions.

ACKNOWLEDGEMENTS: I thank the participants of the presentation of this paper on the XXII. Deutscher Kongress für Philosophie in Munich for their inspiring discussion.

\section{REFERENCES}

Adams, Frederick (1986): Intention and Intentional Action. The Simple View. In: Mind and Language 1: 281-301.

Adams, Frederick (1994): Trying, Desire, and Desiring to Try. In: Canadian Journal of Philosophy 24: 613-626.

Adams, Frederick (2007): Trying With the Hope. In: Mark Timmons; J. Greco; Alfred Mele (eds.): Rationality and the Good. Oxford: Oxford U.P. Pp. 143-162.

Adams; Frederick; Alfred R. Mele (1989): The Role of Intention in Intentional Action. In: Canadian Journal of Philosophy 19: 511-531.

Brand, Myles: Intending and Acting. Toward a Naturalized Action Theory. Cambridge, MA; London: MIT Press.

Aristotle (E.N.): Nicomachean Ethics. Tranlsated by W. D. Ross, revised by J. O. Urmson. In: Aristotle: The Complete Works of Aristotle. The Revised Oxford Translation. Ed. by Jonathan Barnes. Princeton, NJ: Princeton U.P. 1984. Vol. 2. Pp. 1729-1867.

Bratman, Michael E. (1987): Intention, Plans, and Practical Reason. Cambridge, MA; London: Harvard U.P.

Gollwitzer, Peter M. (1999): Implementation Intentions. Strong Effects of Simple Plans. In: American Psychologist 54: 493-503.

Kant, Immanuel (Groundwork): Grundlegung zur Metaphysik der Sitten. $\left({ }^{1} 1785 ;{ }^{2} 1786.\right)$ In: Idem: Werkausgabe. Ed. by Wilhelm Weischedel. Vol. VII. Frankfurt, Main: Suhrkamp 21977. Pp. 7-102. - Or in: Idem: Kants Werke. Akademie-Textausgabe. Vol. 4. Unchanged reprint of the 1903 edition. Berlin: de Gruyter 1968. Pp. 385-464. - English translation: Groundwork for the Metaphysics of Morals. Edited and translated by Thomas E. Hill and Arnulf Zweig. Oxford [etc.]: Oxford U.P. 2003.

Leibniz, Gottfried Wilhelm (<1704> 1996): Nouveaux essais sur l'entendement humain. (1704; 1765.) In: Idem: Philosophische Schriften. Bd. III, in zwei Teilbänden. Ed. and transl. by Wolf von Engelhardt and Hans Heinz Holz. Darmstadt: Wissenschaftliche Buchgesellschaft 1959; 2 1985. - Engl. translation: New essays on human understanding. Translated and edited by Peter Remnant and Jonathan Bennett. Cambridge; New York: Cambridge University Press 1996.

Locke, John (<1689> 2004): An essay concerning human understanding. (1689.) Edited by Alexander Campbell Fraser; introduction by Walter R. Ott. New York: Barnes \& Noble 2004.

Lumer, Christoph: Tre tipi di teorie filosofiche. (Three Types of Philosophical Theories.) In: Richard Davies (ed.): Analisi. Annuario e Bollettino della Società Italiana di Filosofia Analitica (SIFA) 2011. Milano; Udine: Mimesis 2011. Pp. 45-75.

McCann, Hugh (1995): Intention and Motivational Strength. In: Journal of Philosophical Research 20: 571-584.

McCann, Hugh (1998): The Works of Agency. On Human Action, Will, and Freedom. Ithaca; London: Cornell U.P.

Mele, Alfred R. (1992): Springs of Action. Understanding Intentional Behavior. New York; Oxford: Oxford University Press. 